\title{
Extending the Ashrae Tp8 method for vertical borefield design to uniform BHE temperature boundary conditions
}

\author{
Davide Rolando
}

Marco Fossa

\author{
Antonella Priarone
}

\begin{abstract}
The Ashrae method is a fast algorithm for calculating the overall length of closed-loop borehole heat exchangers, considering the ground thermal response and the building thermal load profile. The method includes a corrective variable called Temperature Penalty $\left(T_{\mathrm{p}}\right)$ to account for the thermal interaction between boreholes. Several authors proposed different approaches for calculating this parameter, but the majority is inaccurate or too complex. Recently, the same Authors suggested a very simple method, called $T_{\mathrm{p} 8}$. The coefficients included in the original formula were optimized against g-functions obtained by spatial superposition of a single source always working at the same heat rate. In this paper, the early $T_{\mathrm{p} 8}$ method is improved by the calculation of new constants based on g-functions calculated for uniform temperature borehole conditions. A large dataset of 300 borefield configurations have been considered for optimization and validation purposes. In this case, all the BHEs are at the same temperature and the overall heat transfer rate of the field is constant in time. Compared with EED software outputs, the results from present $T_{\mathrm{p} 8}$ method show a good accuracy (within 3\% for the overall BHE field length) while maintaining a great simplicity in applying the method at engineering design level.
\end{abstract}

\section{INTRODUCTION}

The sizing process of a Ground Coupled Heat Pump (GCHP) needs the knowledge of the building loads, the heat pump characteristics and the ground thermophysical properties. The element that influences more the profitability of the plant from both the energy efficiency and financial sustainability point of view is the correct design of the boreholes (BHEs) field.

Different methods have been proposed to this aim, including commercial design tools as EED (1994) and GLHEPRO (2000). These softwares are powerful but their algorithms are complex and above all not suitable to be implemented in engineering level calculations (e.g. calculation spreadsheets) or suggested in Standards.

Kavanaugh and Rafferty (1997) proposed a method that later became the Ashrae reference. This method is very simple but contains some critical elements, in particular a correction parameter named temperature penalty $T_{\mathrm{p}}$. The physical meaning of this parameter is not clearly disclosed in the Ashrae method and the original methodology suggested by Kavanaugh and Rafferty for the $T_{\mathrm{p}}$ calculation appears arguable and inaccurate in the results it is able to provide.

During the years, some critical analyses to the Ashrae method have been carried out, including the ones by Bernier et al. (2008), Fossa (2011) and Capozza et al. (2012).

More recently, Ahmadfard and Bernier $(2014,2018)$ proposed modifications to the Ashrae method that involve the elimination of the temperature penalty term and the analytical evaluation of the long term ground resistance by the superposition of the finite line source (FLS) solution on borehole segments to obtain the "real" $g$-function for the BHE field at time equal to 10 years.

D. Rolando (davide.rolando@energy.kth.se) is Researcher at KTH Royal Institute of Technology, Sweden

M. Fossa (marco.fossa@unige.it) is Full Professor and A. Priarone (a.priarone@unige.it) is Researcher at DIME, University of Genova, Italy 
A different approach has been proposed by Fossa and Rolando (2014, 2015) who kept the temperature penalty parameter and proposed a method based on the original Ashrae implementation. Comparisons with EED software results showed the reliability of the improved $T_{\mathrm{p} 8}$ method, which maintains with respect to other formulations a great simplicity and the possibility to be implemented in calculation spreadsheets and employed in Standard method (Fossa et al. 2017).

In the present paper, a further improvement to the original version of the method is proposed, with a new set of constants obtained considering as a reference the g-functions calculated for uniform temperature at the BHE wall, hereafter called BC III g-functions (Eskilson 1987, Hellstrom 1989, Cimmino and Bernier 2014, Lamarche 2017).

\section{THEORETICAL BACKGROUND}

To size a borehole heat exchangers (BHEs) field, one of the most important elements is the correct modeling of the transient response of the ground to the presence of the heat exchangers. Neglecting the influence of the groundwater, the analysis can be reduced to the resolution of a transient three-dimensional heat conduction problem.

Usually, a single BHE is first considered to obtain a basic solution that can be then superposed in space and time. This basic solution can be achieved analytically or numerically, applying to the BHE suitable boundary conditions and considering the ground domain as one-dimensional (radial direction) or two-dimensional (radial and axial one). In the following, the main models are briefly presented.

The simplest case is the one-dimensional transient response of the ground to an infinite line source (ILS), as discussed by Thomson (Lord Kelvin), (1882, 1911), Carslaw and Jaeger (1947) and Ingersoll et al. (1954). In this case, the applied boundary condition is an imposed constant heat transfer rate for unit length $\dot{Q}^{\prime}$.

Carslaw and Jaeger (1947) developed a solution for the hallow infinite cylinder and analytically solved the problem for either the constant heat rate or constant temperature boundary condition. Later Ingersoll et al. (1954) provided tabulated values of the related solutions.

To take into account the actual finite length of the BHE, the finite line source (FLS) model has been proposed by Zeng (2002) and then reformulated by Lamarche and Beauchamp (2007). Finally, Claesson and Javed (2011) proposed an analytical solution that is commonly used as basic solution in the space superposition process.

Recently, Priarone and Fossa $(2015,2016)$ proposed to model the BHE as a finite hallow cylinder (FCS), imposing either constant heat rate or temperature and solving the problem numerically. In particular, the imposed temperature boundary condition provides a non-uniform heat transfer rate along the depth of the BHE.

The transient temperature field in the ground around the BHE, obtained analytically or numerically, can be provided by defining a generic temperature response factor $\Gamma$, with reference to the average heat rate per unit length:

$$
\Gamma=\frac{2 \pi k_{g r}\left(T-T_{g r, \infty}\right)}{\dot{Q}_{\text {ave }}^{\prime}}
$$

In a similar way, the average temperature at the BHE boundary in a BHEs field can be described by using a family of temperature response factors called $g$-function, first introduced by Eskilson (1987).

The $g$-functions are obtained by superposition of a basic solution and depend on geometrical parameters and operating conditions of the BHEs field:

$$
\frac{2 \pi k_{g r}\left[T_{\text {ave }}\left(r_{b}\right)-T_{g r, \infty}\right\rfloor}{\dot{Q}_{\text {ave }}^{\prime}}=g\left(\ln \left(9 \mathrm{Fo}_{H}\right), r_{b} / H, B / H, \text { borefield geometry }\right)
$$

In the Eskilson original work the superposition was realized numerically to obtain a uniform temperature for all the BHEs and a total heat transfer rate constant in time for the whole borefield. This condition replicates correctly the actual operating condition of the GCHP with BHEs connected in parallel and a nearly constant COP not greatly depending on the temperature of the fluid.

However, usually the building load is variable in time; so, after obtaining the $g$-function for a constant total heat transfer rate of the borefield, the transient ground response to a variable load can be obtained by a superposition in time, according to the method described for example by Yavuzturk and Spitler (1999). 
During the years, several efforts have been made in literature to reproduce the Eskilson $g$-functions, according to different approaches, briefly described in the following and sketched in Table 1.

The most common method is to simply superpose in space the FLS solution obtained for a single BHE, keeping uniform heat transfer rate for all the BHE of the field (BC I). Fossa et al. (2009) and Cimmino and Bernier (2013) tried to reproduce the actual behavior of the borefield and calculated the $g$-functions by applying different uniform heat transfer rates to the BHEs according to their position in the field (BC II). Unfortunately, this approach does not yet reproduce the Eskilson $g$-functions.

Thus, Cimmino and Bernier (2014) proposed an improvement to their method. They considered a "segmented" heat transfer rate boundary condition applied to each BHE to obtain a nearly uniform temperature distribution in the whole field again keeping the total heat transfer rate constant in time (BC III.) This method provides results very similar to the Eskilson ones since it applies the original swedish approach. A further improvement to this approach has been proposed by Lamarche (2017) with a piecewise-linear profile applied to each BHE. This method reduces the number of segments and simplifies the matrix inversion process devoted to segment heat transfer rate evaluation.

Table 1. Different approach for the g-functions evaluation

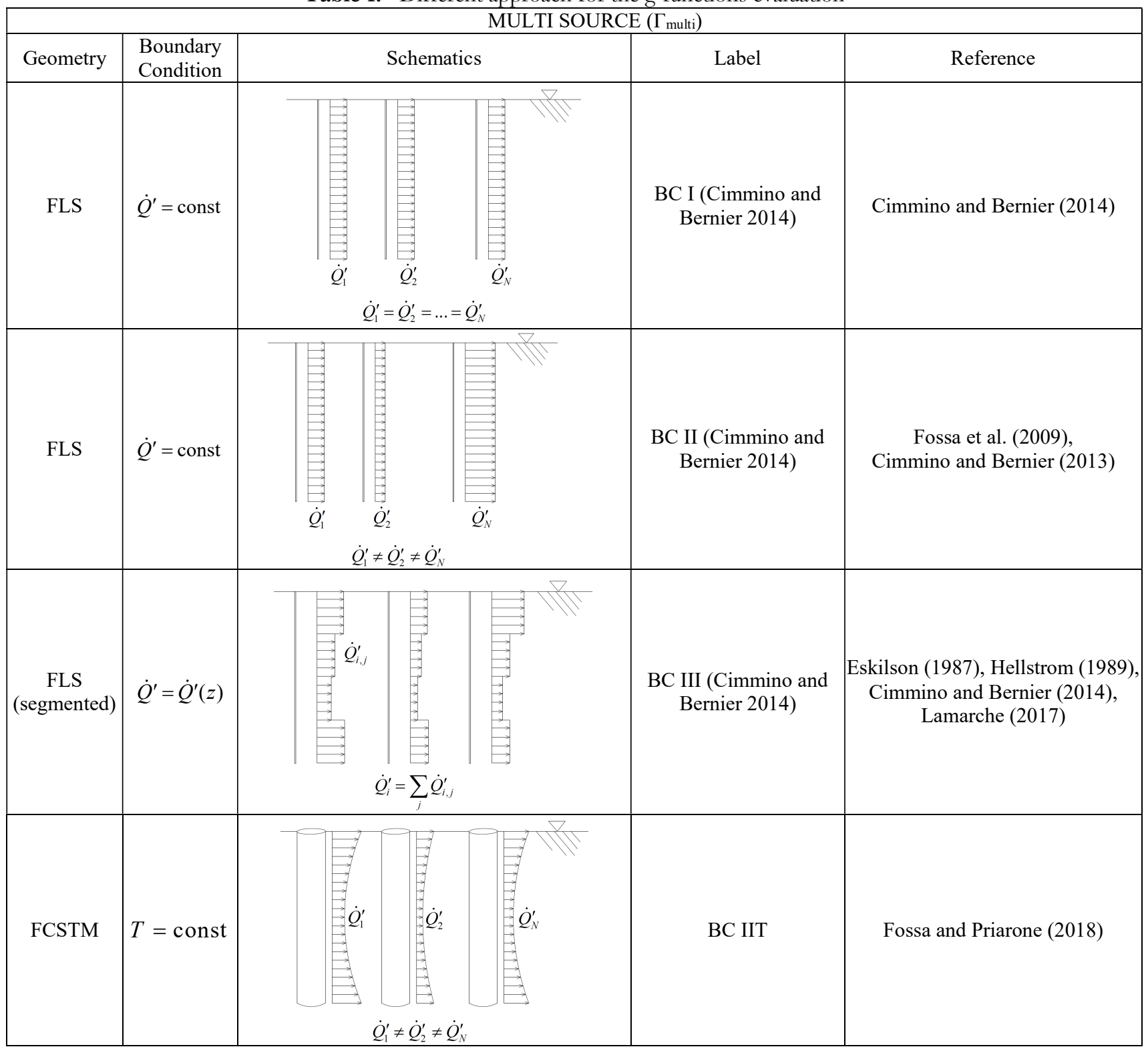


A different method is proposed by Fossa and Priarone (Fossa and Priarone 2018) who suggest as basic solution their finite hallow cylinder with imposed temperature boundary condition (FCST). This solution is superposed in space after having iteratively evaluated the heat transfer rate for each BHE of the field to ensure a constant in time global load to the ground (BC IIT).

The peculiarity of the method is that the basic single BHE temperature response factor $\Gamma$ is provided in tabular form at given radial distances from the source and in a wide range of Fourier numbers, avoiding in such a way the numerical integration of FLS solution.

\section{THE ASHRAE $T_{P 8}$ METHOD}

The simplest method to size a borefield is the Ashrae method, first proposed by Kavanaugh and Rafferty (1997) and based on the knowledge of the building heat load requirements in time.

Bernier (2006) proposed the following formulation of the Ashrae method:

$$
L=\frac{\left\{\dot{Q}_{y} R_{y}+\dot{Q}_{m} R_{m}+\dot{Q}_{h}\left(R_{h}+R_{b}\right)\right\}}{T_{g r, \infty}-T_{f, a v e}\left(\tau_{N}\right)-T_{p}}
$$

where $T_{\mathrm{gr}, \infty}$ is the undisturbed ground temperature, $T_{\mathrm{f}, \mathrm{ave}}$ is the average fluid temperature and $R_{\mathrm{b}}$ is the effective thermal resistance of the borehole.

$\dot{Q}_{y}, \dot{Q}_{m}$ and $\dot{Q}_{h}$ are the average heat transfer rates from (or to) the ground in a given period of 10 years, one month and 6 hours, respectively. These basic thermal pulses are assumed suitable to represent the building thermal history. $\tau_{N}$ is the total considered time period (10 years +1 month +6 hours).

$R_{y}, R_{m}, R_{h}$ are ground resistances evaluated according to the ICS model at the above time intervals.

Finally, $T_{\mathrm{p}}$ represents the temperature penalty, which accounts for "interference of adjacent borehole" (Ashrae Handbook 2015).

The ICS model (and its well known $G$ solution) is suitable to represent the ground thermal response in the short and medium time intervals but not for the long term analysis, i.e. for a time period of 10 years. Thus, evaluating the resistance $R_{\mathrm{y}}$ using the $G$ solution provides incorrect results and leads to significant error (up to $100 \%$ or more, when the BHE number is large and $\dot{Q}_{y}$ term is comparable as order of magnitude with $\dot{Q}_{m}$ and $\left.\dot{Q}_{h}\right)$ in the calculation of the total borehole length.

Fossa (2011) first pointed out the real meaning of the temperature penalty parameter which represents the needed correction in the long term analysis comparing the $G$ solution and the proper $g$-function for the BHE field:

$$
T_{p}(L)=\frac{\dot{Q}_{y}\left(\frac{g\left(\tau_{N}\right)}{2 \pi}-G\left(\tau_{N}\right)\right)}{L k_{g r}}
$$

It is interesting to outline that $T_{\mathrm{p}}$ is proportional to the long term heat loads $\dot{Q}_{y}$ thus, considering a building with balanced heating and cooling request leads to small temperature penalty values.

Therefore, the correct evaluation of the temperature penalty parameter becomes mandatory for the correct sizing of the BHE field, especially for buildings with unbalanced seasonal loads.

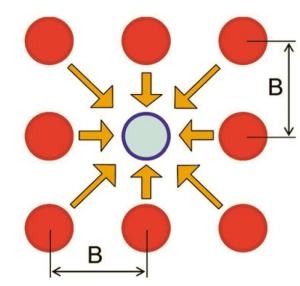

Figure 1. Superposition of thermal effects behind the concept of $\theta_{8}$ temperature excess. 
Fossa and Rolando (2015) and Fossa (2016) proposed a method based on the interaction of each borehole in a field with the eight neighboring ones (for this reason called $T_{\mathrm{p} 8}$ ) according to Figure 1. With respect to the central one, four BHEs are at distance $B$ and four at distance $B \sqrt{2}$.

The excess temperature for the central BHE is calculated by the superposition of the corresponding ILS solution for the other BHEs:

$$
\theta_{8}=T\left(r_{b}\right)-T_{g r, \infty}=\dot{Q}_{y} \frac{E_{1}\left(\tau_{N}, B\right)+E_{1}\left(\tau_{N}, B \sqrt{2}\right)}{\pi k_{g r} L}
$$

The $T_{\mathrm{p} 8}$ formulation is intentionally similar to the Kavanaugh and Rafferty (1997) corresponding one:

$$
T_{p 8}=\theta_{8} \frac{a N_{4}+b N_{3}+c N_{2}+d N_{1}}{N_{t o t}}
$$

where $N_{4}, N_{3}, N_{2}$ and $N_{1}$ are the number of boreholes surrounded by only 4 other ones, only 3 other ones, and so on, respectively.

The constant $a, b, c, d$ are evaluated by optimum search by comparison with the "correct" BC III $g$-functions for a large number of different BHE field configurations, considering a reference BHE depth $H_{\text {ref }}$ equal to $100 \mathrm{~m}$. For different BHE depths, Fossa and Rolando (2015) suggest the following correction in the evaluation of the Fourier number to be used in the $E_{1}$ calculation (Eq.5):

$$
F^{*}=F o\left(\tau_{N}, R\right) \cdot\left(\frac{H_{r e f}}{H}\right)
$$

Where $\mathrm{R}$ can be either $B$ or $B \sqrt{2}$. Worth noticing, the above correction also works for coping with BHE filed configurations where $n / H$ is different from the reference 0.0005 value at which the constants in Eq.(6) have been calculated. A demonstration in this sense is not provided here for the sake of brevity.

\section{BUILDING AND VALIDATING THE NEW TP8 METHOD}

A large set of BHE configurations has been considered in order to calculate the 4 constants to be employed in Eq. (6). For each configuration the corresponding BC III $g$-function has been calculated and adopted as a reference for evaluating the correct value of the $T_{\mathrm{p}}$ according to Eq. (4) and for estimating the uncertainty of the proposed model. Some of these reference $\mathrm{g}$-functions are from Eskilson thesis, some are from EED database, and all of them have been cross checked. As an example in Figure $2 \mathrm{a}$ and $2 \mathrm{~b}$ some reference $\mathrm{g}$-function values are presented together with the original Eskilson profiles for two rectangular configurations and different values of the $B / H$ parameter.

The BHE fields include square and rectangular configurations (up to 10x12 BHEs) and non-rectangular configurations. The non-rectangular configurations include: in-line (up to 16x1), L shaped (up to 10x10L), U shaped (up to 10x10U) and empty rectangles (up to 10x10O).

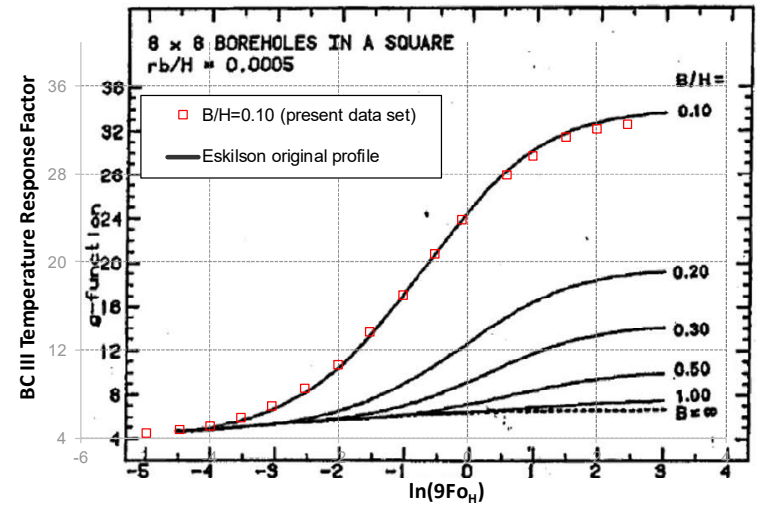

(a)

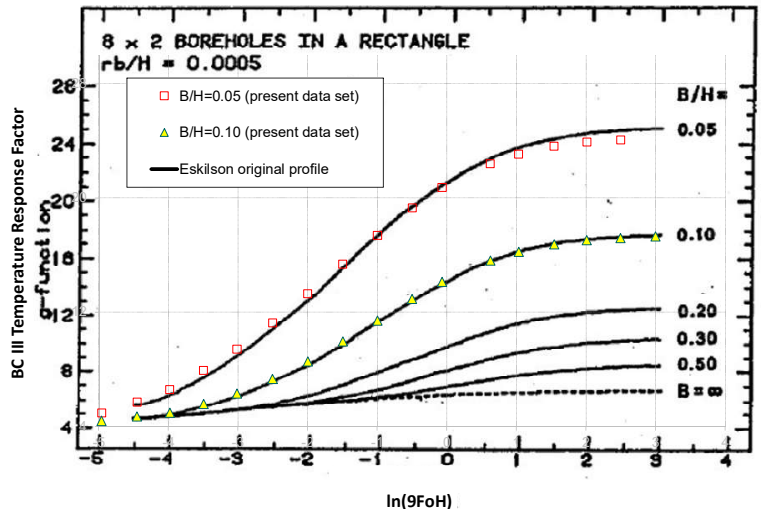

(b)

Figure 2. Comparison between present data set values and original Eskilson $g$-function profiles for different values of the $B / H$ parameter. (a) $8 \times 8$ in a square; (b) $8 \times 2$ in a rectangle. 
Similarly, to the work proposed by Fossa and Rolando (2015) slender rectangular configuration with an aspect ratio greater than 3 are accounted as non-rectangular configurations. Compared to the set of configurations employed in Fossa and Rolando (2015) the range considered in this paper is wider and includes slender rectangular shapes with lower dimension greater than 2, such as 10x3 and 12x3.A BHE depth $(H)$ equal to $100 \mathrm{~m}$ has been adopted for all the configurations and different BHE spacing $(B)$ has been employed in order to have dimensionless BHE spacings $(B / H)$ of $0.03,0.05,0.075,0.1$ and 0.125 . As a result, an overall number of $300 \mathrm{BHE}$ fields have been considered, including 150 rectangular configurations and 150 non-rectangular configurations. A dimensionless reference radius $(\mathrm{b} / H)$ ref has been adopted equal to 0.0005 for all the calculations.

Moreover, for all the calculations a ground thermal conductivity of $2.7 \mathrm{~W} /(\mathrm{mK})$ and a ground thermal diffusivity of $1.65 \mathrm{E}-6 \mathrm{~m} 2 / \mathrm{s}$ have been used. A reference unbalanced heat load profile (with no cooling mode) has been adopted to design each of the 300 configurations employing the BC III $g$-function. Worth noticing, given the implicit nature of Eq. (3), the heat load profile has been scaled for each configuration in order to obtain a design BHE depth of $100 \mathrm{~m}$ as a result of an iterative calculation. Similarly to Fossa and Rolando (2015), an optimization procedure has been implemented in a proprietary code in order to minimize the objective function $F$ shown in Eq. (8):

$$
F(a, b, c, d)=\frac{1}{B H E_{k}} \sum_{j=1}^{B H E_{k}} \frac{\left|T_{p, j}-T_{p 8, j}\right|}{T_{p, j}}
$$

Where $k$ refers either to the 150 rectangular configurations or to the 150 non-rectangular configurations. The 4 constants $a, b, c$ and $d$ that have been iteratively refined in order to minimize the absolute overall percentage error of the $T_{\mathrm{p} 8}$ with respect to the reference $T_{\mathrm{p}}$.

\section{RESULTS AND DISCUSSION}

The objective function defined in Eq. (8) has been minimized through the refinement of the 4 coefficients $a, b, c$ and $d$. The optimum search procedure, described in the previous section, has been applied separately to rectangular $(\mathrm{R})$ and non-rectangular (non-R) configurations. The optimization procedure has been performed also considering separately the respective dimensionless BHE spacing, following the same procedure adopted in Fossa and Rolando (2015). Table 2 and Table 3 show the raw value obtained by the performed optimization and no further attempt to level the resulting values has been carried out. The inspection of the constant values, for both $\mathrm{R}$ and non- $R$ configurations, reveals the possibility to interpolate the results for any $B / H$ between 0.03 and 0.125 .

The whole set of 300 configurations has been used to calculate the overall errors of the proposed new $T_{\mathrm{p} 8}$ coefficients and to validate the proposed model. Preliminary further comparisons, to be discussed in a future work, confirm the reliability of the present method also outside the perimeter of the reference data set. Figure 3 shows the results of the new $T_{\mathrm{p} 8}$ model in terms of overall BHE length (Figure 3a) and temperature penalty values (Figure 3b). In particular, Figure 3a shows the very good agreement of the design borehole length evaluated with the $T_{\mathrm{p} 8}$ model $\left(L_{8}\right)$ compared to the overall length calculated with the reference model based on the BC III $g$ functions. The overall percentage difference between $L$ and $L_{8}$ is only $2.95 \%$. Similarly, Figure $3 \mathrm{~b}$ shows the same results in terms of temperature penalty values. The comparison shows a good agreement between the $T_{\mathrm{p} 8}$ and the $T_{p}$, especially considering large rectangular configurations. A tendency of exceeding the $\pm 10 \%$ agreement can be noticed for rectangular configurations with relatively low values of temperature penalty (i.e. low overall borehole length). The overall percentage difference between the $T_{\mathrm{p} 8}$ and the $T_{\mathrm{p}}$ values is $9.86 \%$, while the maximum difference is almost $40 \%$, but for only one case among those here considered.

Worth noticing, the results of the overall difference between the proposed method and the reference based on the BC III $g$-functions are very similar to the results obtained by the parameter estimation analysis carried out by Fossa and Rolando (2015) where the reference models were the BC I and BCII $g$-functions. In that case, the overall percentage differences between the $T_{\mathrm{p} 8}$ method and the reference were $2.7 \%$ for the overall borehole length and $9.4 \%$ for the temperature penalty values.

Figure 4 shows the comparison between the original Kavanaugh and Rafferty method (Ashrae first method) and the reference BC III model in terms of overall BHE length and temperature penalty for all the 300 configurations considered in the present analysis. In terms of design borehole length, the underestimation 
tendency and the deviation from the theoretical agreement for medium and large borefield (e.g. $L>1000 \mathrm{~m}$ ) is confirmed and shown in Figure 4a. The comparison in terms of temperature penalty shown in Figure 4b confirms also the low agreement between the $T_{\mathrm{pA}}$ and the $T_{\mathrm{p}}$ values.

Table 2. Constants to be employed in Eq. (6) for Rectangular (R) configurations

\begin{tabular}{c|c|c|c|c|c}
\hline \multicolumn{7}{c}{ Rectangular configurations } \\
\hline B/H & $\mathbf{0 . 0 3}$ & $\mathbf{0 . 0 5}$ & $\mathbf{0 . 0 7 5}$ & $\mathbf{0 . 1}$ & $\mathbf{0 . 1 2 5}$ \\
\hline $\mathbf{a}$ & 4.840 & 3.824 & 3.194 & 2.373 & 2.072 \\
\hline $\mathbf{b}$ & 0.4132 & 0.4045 & 0.4403 & 0.5069 & 0.5118 \\
\hline $\mathbf{c}$ & 0.3041 & 0.2894 & 0.2793 & 0.2618 & 0.2525 \\
\hline $\mathbf{d}$ & 0 & 0 & 0 & 0 & 0 \\
\hline
\end{tabular}

Table 3. Constants to be employed in Eq. (6) for non-R configurations

\begin{tabular}{|c|c|c|c|c|c|}
\hline \multicolumn{6}{|c|}{ Non-Rectangular and slender Rectangular configurations $(6 \times 2,7 \times 2,10 \times 3,12 \times 3)$} \\
\hline $\mathrm{B} / \mathrm{H}$ & 0.03 & 0.05 & 0.075 & 0.1 & 0.125 \\
\hline a & 3.173 & 2.571 & 2.275 & 1.752 & 1.567 \\
\hline b & 1.0587 & 0.9129 & 0.8241 & 0.7166 & 0.6702 \\
\hline c & 0.7192 & 0.6037 & 0.5140 & 0.4081 & 0.3645 \\
\hline d & 0.05 & 0.05 & 0.05 & 0.05 & 0.05 \\
\hline
\end{tabular}
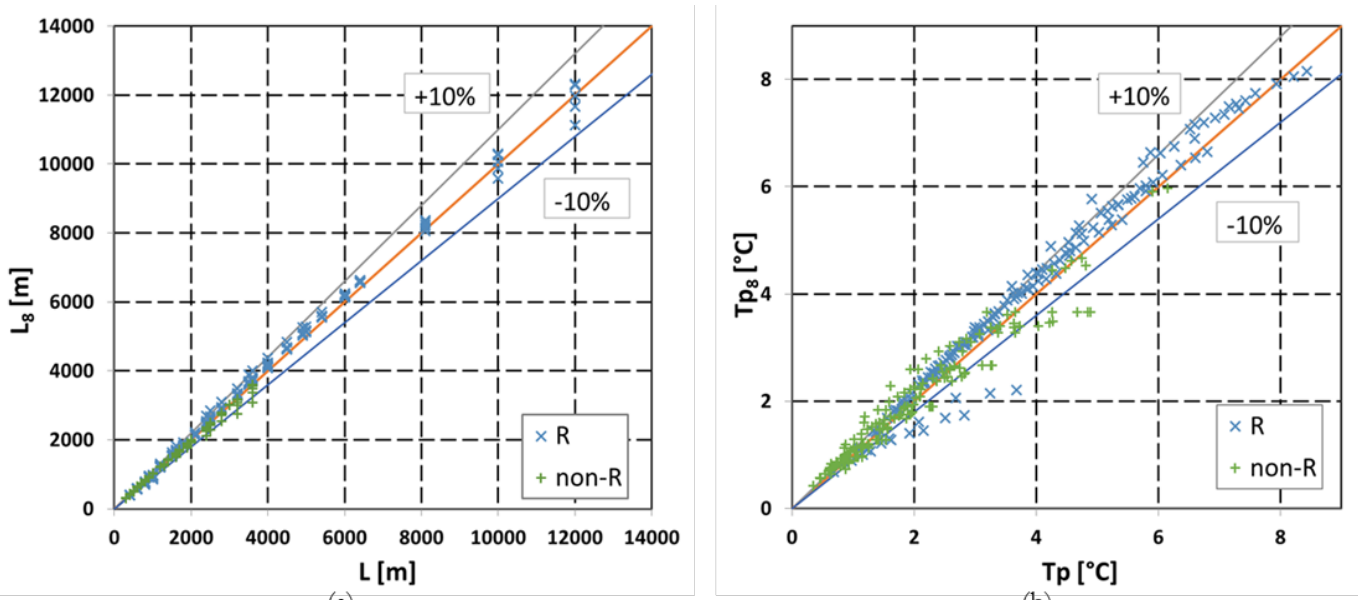

(b)

Figure 3. Comparison between calculated overall length $L$ (a) and temperature penalty $T_{\mathrm{p}}$ (b) according to the reference model and the proposed $T_{\mathrm{p} 8}$ model for $300 \mathrm{BHE}$ configurations.

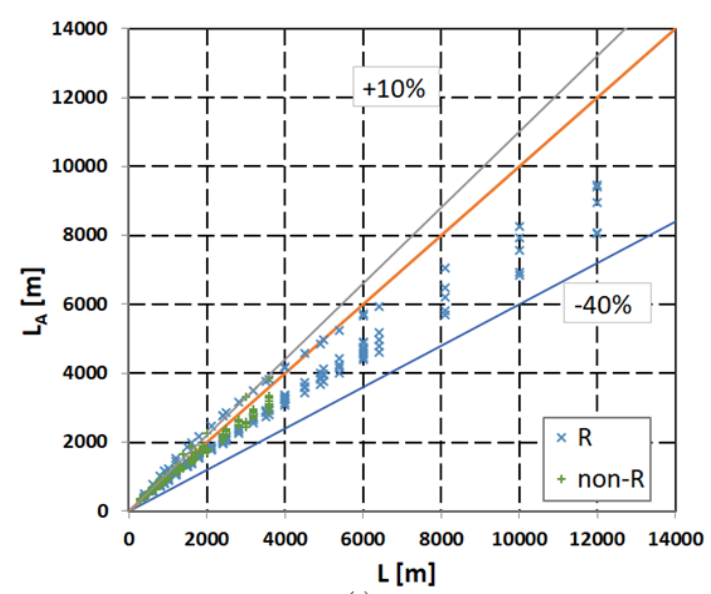

(a)

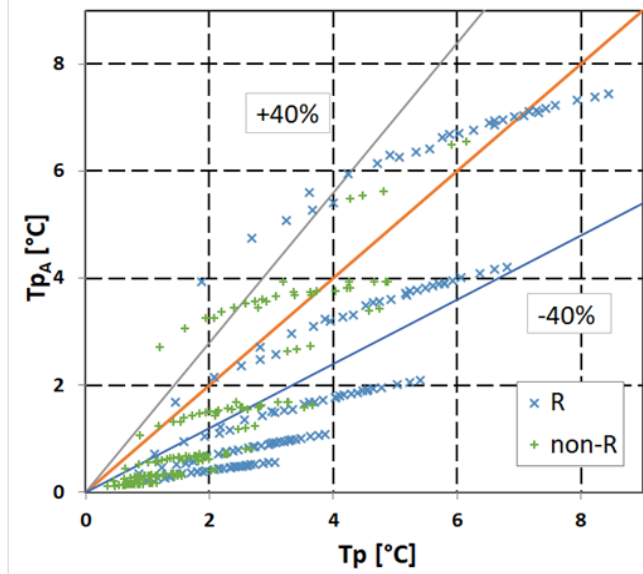

(b)

Figure 4. Comparison between calculated overall length $L$ (a) and temperature penalty $T_{\mathrm{p}}$ (b) according to the reference model and the original Kavanaugh and Rafferty model for 300 BHE configurations. 


\section{CONCLUSIONS}

In this paper a new version of the modified Ashrae method is discussed in order to propose a reliable and simple procedure for the design of BHE fields. The new method is based on the constant refinement procedure already proposed by Fossa and Rolando (2015). In this paper, a new set of constant for the evaluation of the temperature penalty has been obtained through an optimum search procedure based on the BC III $g$-functions and considering $300 \mathrm{BHE}$ configurations. It has been demonstrated that the implemented approach for calculating the new constants used in the evaluation of the temperature penalty values is reliable and consistent.

The average percentage difference of the proposed method is less than $3 \%$ compared to the reference one and a very good agreement for a large variety of BHE configurations has been proven. For these reasons, the present method is proposed as a simple and valuable tool for BHE field design.

\section{NOMENCLATURE}

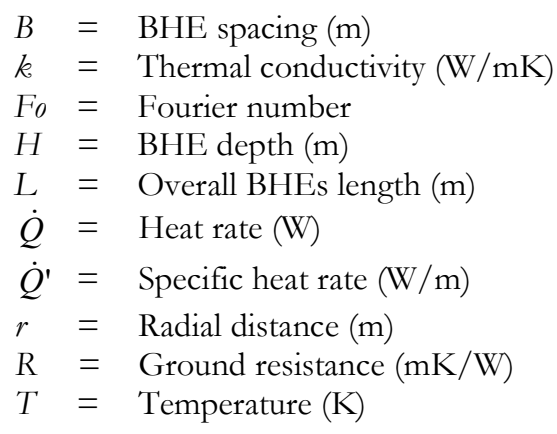

\section{Subscripts}

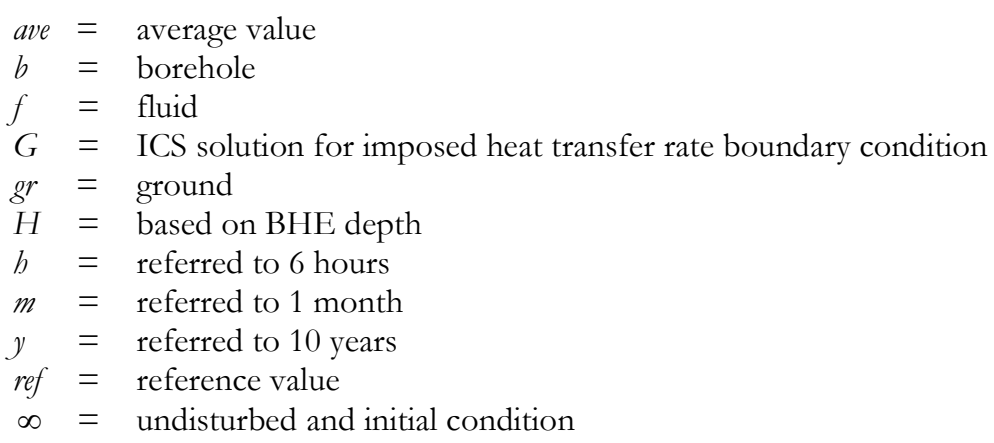

\section{REFERENCES}

Ahmadfard, M. and M. Bernier. 2014. An alternative to ASHRAE's design length equation for sizing borehole beat exchangers. ASHRAE Annual Conference, Seattle, WA, June 28-July 2, 1-8.

Ahmadfard, M. and M. Bernier. 2018. Modifications to ASHRAE's sizing method for vertical ground heat exchangers. Science and Technology for the Built Environment.

ASHRAE. 2015. Chapter 34, Ashrae Handbook-HVAC Applications: Geothermal Energy Atlanta: ASHRAE.

Bernier, M. 2006. Closed-loop ground-coupled heat pump systems. ASHRAE Journal 48(9):12-19.

Bernier, M., A. Chahla, and P. Pinel. 2008. Long-term ground temperature changes in geo-exchange systems. ASHRAE Transactions 114: 342-350.

Capozza, A., M. De Carli and A. Zarrella. 2012. Design of borehole heat exchangers for ground-source heat pumps: A literature review, methodology comparison and analysis on the penalty temperature. Energy and Buildings 55: 369-379.

Carslaw, H.S. and J.C. Jaeger. 1947. Conduction of heat in solids, Claremore Press, Oxford, U.K.

Cimmino, M. and M. Bernier. 2014. A semi-analytical method to generate g-functions for geothermal bore fields. J. of Heat and Mass Transfer: 641-650.

Cimmino, M., M. Bernier and F. Adams. 2013. A contribution towards the determination of $g$-functions using the finite line source. Applied Thermal Engineering 51(1-2): 401-412. 
Claesson, J. and S. Javed. 2011. An analytical method to calculate borehole fluid temperatures for time-scales from minutes to decades, ASHRAE Transactions 117 (2): 279-288.

Eskilson, P. 1987. Thermal analysis of heat extraction boreholes. Ph.D. Thesis. Lund University of Technology, Sweden.

Fossa, M. 2016. Correct design of vertical borehole heat exchanger systems through the improvement of the ASHRAE method. Science and Technology for the Built Environment. DOI: 10.1080/23744731.2016.1208537.

Fossa, M. and A. Priarone. 2018. Constant temperature response factors for fast calculation of sparse bhe field G-functions. Submitted to Renewable Energy. Manuscript number: RENE-D-18-00806

Fossa, M. and D. Rolando. 2014. Improving the Ashrae method for vertical geothermalborefield design. 11th International Energy Agency Heat Pump Conference, Montreal, Canada.

Fossa, M. and D. Rolando. 2015. Improving the Ashrae method for vertical geothermal borefield design. Energy and Buildings 93 315-323.

Fossa, M. 2011. The temperature penalty approach to the design of borehole heat exchangers for heat pump applications. Energy and Buildings 43:1473-1479.

Fossa, M., D. Rolando, A. Priarone. 2017. Investigation on the Effects of Different Time Resolutions in the Design and Simulation of Bhe Fields. In: IGSHPA Conference, Denver (CO).

Fossa, M., O.Cauret and M.Bernier. 2009. Comparing The Thermal Performance of Ground Heat Exchangers of Various Lengths. In: Effstock Conference, Stockholm.

Hellström, G. and B. Sanner. 1994. Earth Energy Designer: Software for Dimensioning of Deep Boreholes for Heat Extraction, Department of Mathematical Physics, Lund University, Sweden.

Ingersoll L.R., O.J. Zobel and A.C. Ingersoll. 1954. Heat conduction with engineering, geological, and other applications, McGraw-Hill, New York.

Kavanaugh, S.P. and K. Rafferty. 1997. Ground source heat pumps design of geothermal system for commercial and institutional buildings. ASHRAE Hanbook, Atlanta, GA.

Lamarche L., and B. Beauchamp. 2007. A new contribution to the finite line-source model for geothermal boreholes. Energy and Buildings 39: 188-198.

Lamarche, L. 2017. g-function generation using a piecewise-linear profile applied to ground heat exchangers. Int. J. of Heat and Mass Transfer 115(B): 354-360.

Priarone, A. and M. Fossa. 2015. Modelling the ground volume for numerically generating single borehole heat exchanger response factors according to the cylindrical source approach. Geothermics 58: 32-38.

Priarone, A. and M. Fossa. 2016. Temperature response factors at different boundary conditions for modelling the single borehole beat exchanger. Applied Thermal Engineering 103: 934-944.

Spitler J.D. 2000. GLHEPRO-a design tool for commercial building ground loop beat exchangers. in: Proc. of 4th Int. Heat Pumps in Cold Climates Conference, Aylmer, Quebec, 17th-18th August.

Thomson, W. (Lord Kelvin). 1882-1911. Mathematical and Physical Papers. Cambridge University Press, London.

Yavuzturk, C. and J.D. Spitler. 1999. A short time step response factor model for vertical ground loop heat exchangers. ASHRAE Transactions 105: 475-485.

Zeng, H., N. Diao and Z. Fang. 2003. Heat transfer analysis of boreholes in vertical ground heat exchangers, International Journal of Heat and Mass Transfer 46: 4467-4481. 